\title{
Effect of Threat on Right dlPFC Activity during Behavioral Pattern Separation
}

\author{
(D) Nicholas L. Balderston, Abigail Hsiung, Monique Ernst, and Christian Grillon \\ Section on Neurobiology of Fear and Anxiety, National Institute of Mental Health, National Institutes of Health, Bethesda, Maryland 20892
}

It has long been established that individuals with anxiety disorders tend to overgeneralize attributes of fearful stimuli to nonfearful stimuli, but there is little mechanistic understanding of the neural system that supports overgeneralization. To address this gap in our knowledge, this study examined effect of experimentally induced anxiety in humans on generalization using the behavioral pattern separation (BPS) paradigm. Healthy subjects of both sexes encoded and retrieved novel objects during periods of safety and threat of unpredictable shocks while we recorded brain activity with fMRI. During retrieval, subjects were instructed to differentiate among new, old, and altered images. We hypothesized that the hippocampus and dorsolateral prefrontal cortex (dIPFC) would play a key role in the effect of anxiety on BPS. The dIPFC, but not the hippocampus, showed increased activity for altered images compared with old images when retrieval occurred during periods of threat compared with safety. In addition, accuracy for altered items retrieved during threat was correlated with dIPFC activity. Together, these results suggest that overgeneralization in anxiety patients may be mediated by an inability to recruit the dlPFC, which mediates the cognitive control needed to overcome anxiety and differentiate between old and altered items during periods of threat.

Key words: anxiety; dlPFC; fMRI; pattern separation; threat of shock

\section{Significance Statement}

Anxiety and posttraumatic stress disorder patients generalize fear to nonfearful fear stimuli, making it difficult to regulate anxiety. Understanding how anxiety affects generalization is key to understanding the overgeneralization experienced by these patients. We examined this relationship in healthy subjects by studying how threat of shock affects neural responses to previously encountered stimuli. Although previous studies point to hippocampal involvement, we found that threat affected activity in the dorsolateral prefrontal cortex (dIPFC), rather than the hippocampus, when subjects encountered slightly altered versions of the previously encountered items. Importantly, this dIPFC activity predicted performance for these items. Together, these results suggest that the dIPFC is important for discrimination during elevated anxiety and that overgeneralization may reflect a deficit in dlPFC-mediated cognitive control.

\section{Introduction}

The ability to distinguish between threatening and nonthreatening events is critical for the regulation of anxiety (Grillon et al., 2009; van Meurs et al., 2014). Individuals with stress or anxiety

Received March 15, 2017; revised July 14, 2017; accepted July 20, 2017.

Author contributions: N.L.B., M.E., and C.G. designed research; N.L.B. and A.H. performed research; N.L.B. and A.H. analyzed data; N.L.B., A.H., M.E., and C.G. wrote the paper.

This study was supported by the Intramural Research Program of the National Institute of Mental Health (NIMH)National Institutes of Health (NIH Grant ZIAMH002798; www.ClinicalTrial.gov identifier: NCT00047853: Protocol ID 02-M-0321). We thank the NIMH Section on Instrumentation for fabricating the custom acoustic startle stimulus devices.

The authors declare no competing financial interests.

Correspondence should be addressed to Nicholas L. Balderston, Section on Neurobiology of Fear and Anxiety, National Institute of Mental Health, National Institutes of Health, 15k North Dr., Bethesda, MD 20892. E-mail: nicholas.balderston@nih.gov.

DOI:10.1523/JNEUROSCI.0717-17.2017

Copyright $\odot 2017$ the authors $\quad 0270-6474 / 17 / 379160-12 \$ 15.00 / 0$ disorders tend to overgeneralize attributes of fearful stimuli to perceptually similar but nonfearful stimuli (Cha et al., 2014; Laufer et al., 2016). Individuals with posttraumatic stress disorder (PTSD) especially suffer from this difficulty, often experiencing intense flashbacks when they encounter trauma reminders (Levy-Gigi et al., 2012, 2015; Kostek et al., 2014; Anastasides et al., 2015). Therefore, a better mechanistic understanding of generalization and discrimination and their interaction with anxiety is integral to understanding the debilitating overgeneralization. A prominent feature of anxiety is that it exists along a continuum across the population and can be manipulated experimentally in healthy individuals. This feature makes it possible to test specific hypotheses regarding the influence of anxiety on cognitive processes using the well validated threat of shock paradigm. This paradigm allows the researcher to induce sustained periods of elevated anxiety in healthy individuals (Grillon, 2008; Schmitz and Grillon, 2012), thus bridging the gap between preclinical 
A Encoding
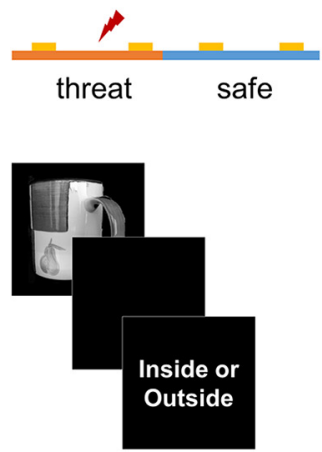

B Retrieval
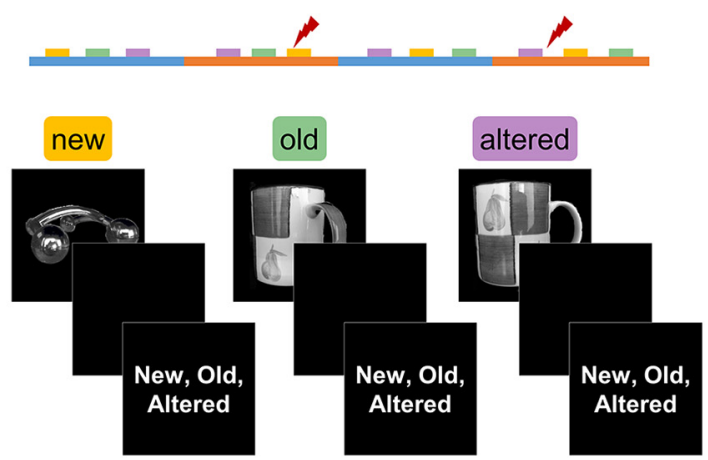

Figure 1. Schematic of experimental design. $\boldsymbol{A}$, Subjects viewed novel items during blocks of threat and safety. $\boldsymbol{B}$, Subjects viewed new, old, and altered items during blocks of threat and safety. New items were those that had not been presented during the encoding phase. Old items were those presented in the same orientation as in the encoding phase. Altered items were rotated slightly compared with when they were presented during encoding. Half of the repeated items (old and altered) were encoded during threat and the other half were encoded during safety. Lightning bolts represent the unpredictable shocks presented in the threat periods.

Table 1. Affective ratings

\begin{tabular}{llr}
\hline Affect & Safe & \multicolumn{1}{c}{ Threat } \\
\hline Anxious & $1.69(0.17)$ & $4.45(0.31)$ \\
Afraid & $1.23(0.09)$ & $3.3(0.34)$ \\
Happy & $7.26(0.28)$ & $5.09(0.28)$ \\
Shock & & $8.78(0.22)$ \\
\hline
\end{tabular}

work in nonhuman animals and clinical work in hard-to-recruit patient populations (Insel, 2014).

One approach to understanding overgeneralization in anxiety is to consider the processes involved in generalization, behavioral pattern separation (BPS) (Stark et al., 2013; van Hagen et al., 2015), and then develop hypotheses based on these processes. In BPS, individuals must discriminate between items previously encountered (old) and subtle variations on these items (altered). The ability to identify these altered items among a stream of new, old, and altered items indexes an individual's tendency toward generalization (Rolls and Kesner, 2006; Rolls, 2013a, 2013b). A link between BPS and stimulus generalization is suggested by basic findings in rodents (Sahay et al., 2011b; van Hagen et al., 2015) and by the recent finding in humans that threat of shock during item retrieval impairs pattern separation (Balderston et al., 2017a). These results suggest that state anxiety affects an individual's discrimination ability, potentially leading to overgeneralization. BPS has been consistently linked to specific circuits in CA3 and the dentate gyrus (Leutgeb et al., 2007; Sahay et al., 2011a; Doxey and Kirwan, 2015), making this structure a prime candidate to offer a mechanistic explanation of the effect of anxiety on BPS.

An alternative approach to understanding overgeneralization in anxiety is to consider the common symptoms seen in anxious patients (Eysenck et al., 2007) and then develop a hypothesis about how these symptoms might affect generalization processes. It is well known that individuals with PTSD and anxiety disorders suffer from deficits in attentional control (Armstrong et al., 2011; Price et al., 2011; Berggren and Derakshan, 2013a; Najmi et al., 2015). This attentional control deficit can also affect performance on other tasks such as those that require working memory (Balderston et al., 2017b) and this deficit is manifest in a reduced ability to recruit activity in the dorsolateral prefrontal cortex (dlPFC) (Balderston et al., 2017b; Kaczkurkin et al., 2017), a region known to support cognitive control (Geier et al., 2007; Barbey et al., 2013; León-Domínguez et al., 2015). Therefore, according to this account, anxiety leads to overgeneralization because it taxes cognitive resources needed to make difficult discriminations based on subtle differences in stimulus characteristics.

The purpose of this study was to test these possibilities by investigating the effect of anxiety on pattern separation in healthy individuals using threat of shock. Subjects encoded and retrieved novel objects during periods of safety and threat of unpredictable shocks while we recorded brain activity with fMRI. During retrieval, subjects were instructed to differentiate among new, old, and altered images. According to the impaired pattern separation hypothesis, subjects should show decreased hippocampal activity to altered items during threat. According to the attention control hypothesis, subjects should show increased activity in the dlPFC to altered items retrieved during threat, which is needed to overcome their anxiety and identify the subtle changes in these stimuli.

\section{Materials and Methods}

\section{Participants}

Forty-one participants were recruited from the Washington, DC, metropolitan area to take part in this study. Inclusion criteria were as follows (1) no current Axis 1 psychiatric disorder as assessed by the SCID-1/NP (American Psychiatric Association, 2013), (2) no medical condition that interfered with the objective of the study as assessed by a physician, (3) no use of illicit drugs or psychoactive medications according to verbal history and negative urine toxicity screening, (4) no brain abnormality on MRI as assessed by a radiologist, and (5) right-handedness. Seven participants were excluded from data analysis, two for failing to respond during the retrieval runs, two because of computer error during data collection, and two for excessive head movement (i.e., $>10 \%$ of TRs censored; see "fMRI preprocessing" section) in the scanner. The final analysis included 32 participants ( 14 females, median age $=28.43$ years, $S D=1.30$ ). All participants gave written informed consent approved by the National Institute of Mental Health (NIMH) Combined Neuroscience Institutional Review Board and were compensated for their time.

\section{Materials}

Stimuli. Images were selected from the Amsterdam Library of Object Images (Geusebroek et al., 2005), a database that contains 1000 images of household objects (e.g., cereal boxes, plants, stuffed toys, etc.) photographed at varying eccentricities. Each subject saw 160 randomly selected images. All images during encoding were photographed at a $45^{\circ}$ eccentricity, as were the old images presented at retrieval. Altered images presented at retrieval were selected randomly to appear at either $15^{\circ}$ or $75^{\circ}$ eccentricity (Fig. $1 B$ ). New images were presented at $45^{\circ}$ eccentricity $50 \%$ of the time and $15^{\circ}$ or $75^{\circ}$ eccentricity the other $50 \%$ of the time to control for nonspecific effects of image rotation (Fig. 1B). Images were presented using the software package Presentation (Version 17; Neurobehavioral Systems) on a back projection system. Responses were collected using a four-button fiber-optic response device (Current Designs).

Shock. Threat of shock was used to induce anxiety during the threat blocks at both encoding and retrieval (Balderston et al., 2016, 2017a, 2017b). Shock was administered through a $100 \mathrm{~ms}, 200 \mathrm{~Hz}$ train of stim- 
ulation using a constant current stimulator (DS7A; Digitimer) and was delivered through two MRI-safe disposable sticker electrodes placed on the surface of the participant's right wrist. Before the experiment, participants completed a calibration procedure to set the intensity of the shock stimulus (Balderston et al., 2016, 2017a, 2017b). The workup consisted of presentations of the shock in incremental increases. After each presentation, participants rated the shock on a scale from 1-10, with 10 being uncomfortable and unpleasant but not painful. Once a rating of 10 was reached, that intensity $(\mathrm{M}=6.82 ; \mathrm{SD}=1.85)$ was used for the remainder of the study.

Psychometric data. Before the start of the study, participants completed an affective rating scale (Balderston et al., 2016, 2017a, 2017b), which was scored from $1-10$. The questions were as follows: (1) How anxious are you? $(1=$ not anxious, $9=$ extremely anxious $)$; (2) How afraid are you? ( $1=$ not afraid, $9=$ extremely afraid); and (3). How happy are you? $(1=$ not happy, $9=$ extremely happy). After each run of the experiment, participants were asked the same affective rating scales, this time responding to how they felt in the safe blacks and threat blocks separately. In addition, they were asked how they would rate the intensity of the electrical stimulation $(1=$ not painful at all, $9=$ uncomfortable but not painful).

\section{Procedure}

Upon arrival, participants were briefed on the experiment and given the pre-experiment psychometric questionnaires. Electrodes were then attached to the wrist to administer the shock. Next, subjects were escorted into the scan room and seated on the gurney, where they completed the shock workup. Afterward, participants were given earplugs and situated in the supine position. A respiratory belt was attached around the chest and pulse oximeter was secured to the right index finger. Scanning started with the collection of a magnetization-prepared rapid gradientecho (MPRAGE) structural scan, followed by two $30 \mathrm{~s}$ echoplanar imaging (EPI) runs. The task included four 9-11 min multi-EPI runs. After task completion, participants were removed from the scanner and debriefed.

The experiment consisted of two runs of encoding and two runs of retrieval. Runs were divided into alternating blocks of safety and threat, signaled by the words "Safe" and "Threat" on the sides of the screen. Subjects were told that they may receive electrical shocks during the threat but not the safe condition (Fig. 1). Each run consisted of four blocks (two per condition) of alternating safe and threat conditions. Each block contained 16 trials during encoding and 20 trials during retrieval. Trials began with a $1 \mathrm{~s}$ fixation cross, followed by an image presented for between 1 and $3 \mathrm{~s}$. The image was followed by a 0.5-1 s maintenance period and then a $1 \mathrm{~s}$ response period (see below). The intertrial interval (ITI) ranged between 2 and $4 \mathrm{~s}$. Between one and three shocks were presented randomly per run during the threat blocks. Shocks either occurred in the trial ITI or during the maintenance period of a trial. All trials containing a shock were discarded from further analyses. Blocks were counterbalanced across participants. Runs were separated by a brief $(<5 \mathrm{~m})$ break during which participants answered psycho-affective questions through an intercom. After the encoding runs, participants were also given instructions for retrieval.

In the encoding phases, participants saw a total of 128 images, 64 images per run. After picture presentation, participants judged whether the image seen belonged inside or outside of a house for $1 \mathrm{~s}$. The judgment response was meant to keep attention and allow for incidental encoding.

In the retrieval phases, participants saw 160 images, 80 images per run. During the response period, participants were prompted to recall whether the image they saw was new (i.e., had not been seen in encoding), old (i.e., identical to the one seen in encoding), or altered (i.e., seen in encoding but had been rotated slightly to the left or right). Of the 160 images, 32 images were new, 64 were old, and 64 were altered images. Half of the images were encoded during threat blocks and half during safe blocks. New items were included as foils and only old and altered images were included in the present analyses. In addition, half of the encoding images presented in safe blocks were presented in retrieval threat blocks and vice versa, creating a $2 \times 2$ factorial design that allowed for all possible encoding/retrieval combinations.

\section{fMRI acquisition}

Four runs of whole brain multi-EPIs were collected using a 3 T Siemens MAGNETOM Skyra fMRI system with a 32-channel head coil. Each image contained 32 interleaved $3 \mathrm{~mm}$ slices (matrix $=64 \mathrm{~mm} \times 64 \mathrm{~mm}$; $\mathrm{FOV}=192 \times 192)$ parallel to the AC-PC line $(\mathrm{TR}=2 \mathrm{~s} ; \mathrm{TEs}=12 \mathrm{~ms}$, $24.48 \mathrm{~ms}, 36.96 \mathrm{~ms}$; flip angle $=70^{\circ}$ ). Encoding runs contained 270 images and retrieval runs contained 338 images. Two 10-image EPI series with opposite phase encoding directions were also collected to correct for geometric distortion in the phase encoding direction. For reference, a multiecho T1-weighted MPRAGE $(\mathrm{TR}=2530 \mathrm{~ms}$; TEs $=1.69 \mathrm{~ms}, 3.55$ $\mathrm{ms}, 5.41 \mathrm{~ms}, 7.27 \mathrm{~ms}$; flip angle $\left.=7^{\circ}\right)$, with $176,1 \mathrm{~mm}$ axial slices $(\mathrm{ma}-$ trix $=256 \mathrm{~mm} \times 256 \mathrm{~mm}$; FOV $=256 \mathrm{~mm} \times 256 \mathrm{~mm}$ ) was acquired.

\section{fMRI preprocessing}

Structural and functional images were preprocessed using the AFNI software package (Cox, 1996). T1 images were first processed with the standard Freesurfer pipeline (Fischl et al., 2002, 2004). The resulting skull-stripped T1 image was then nonlinearly warped to the MNI space using the AFNI program 3dQWarp and the resulting warping parameters were saved for later use. From there, gray matter masks were created using all cortical and subcortical gray matter regions labeled in the aparc + aseg file (Fischl et al., 2002, 2004). These gray matter masks were then resampled to the EPI resolution ( $3 \mathrm{~mm}$ isotropic), dilated by 1 voxel, and then warped to MNI space. A group-level gray matter mask was created by averaging these binary masks and thresholding at 0.75 (i.e., $75 \%$ overlap) (Torrisi et al., 2015).

The reverse phase encoding EPI series were then skull stripped and nonlinearly coregistered using the AFNI program 3dQWarp with the "-plusminus" flag. This procedure combines the images to create a novel reference volume that is "central" to the two input images, therefore minimizing EPI distortion in the phase encoding direction (Hong et al., 2015). This reference image was then warped to the T1 image and all alignment/warp parameters were saved and applied to the $\beta$ images in a single step.

EPI images for each run and each echo were reconstructed, despiked, slice-time corrected, and de-obliqued. Each volume was then reregistered to the first volume and then skull stripped. Using AFNI meica.py script, preprocessed images were then entered into a multiecho independent components analysis that uses the $\mathrm{T} 2{ }^{\star}$ decay of BOLD signals across echo time to differentiate between BOLD-like and non-BOLD-like sources of variability in the EPI time series (Kundu et al., 2012). NonBOLD-like components were then discarded and a new time series was synthesized from the remaining components (Kundu et al., 2012). These four denoised time series corresponding to each run were then coregistered, normalized, and entered into a first-level GLM to identify BOLD responses to the different trial types. 
A
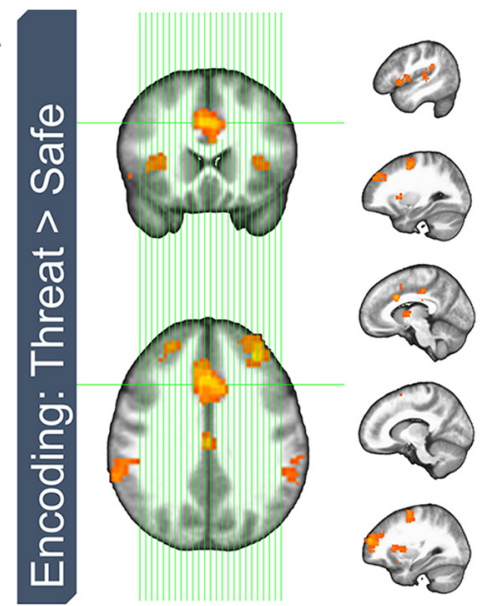

\section{(a)}

B
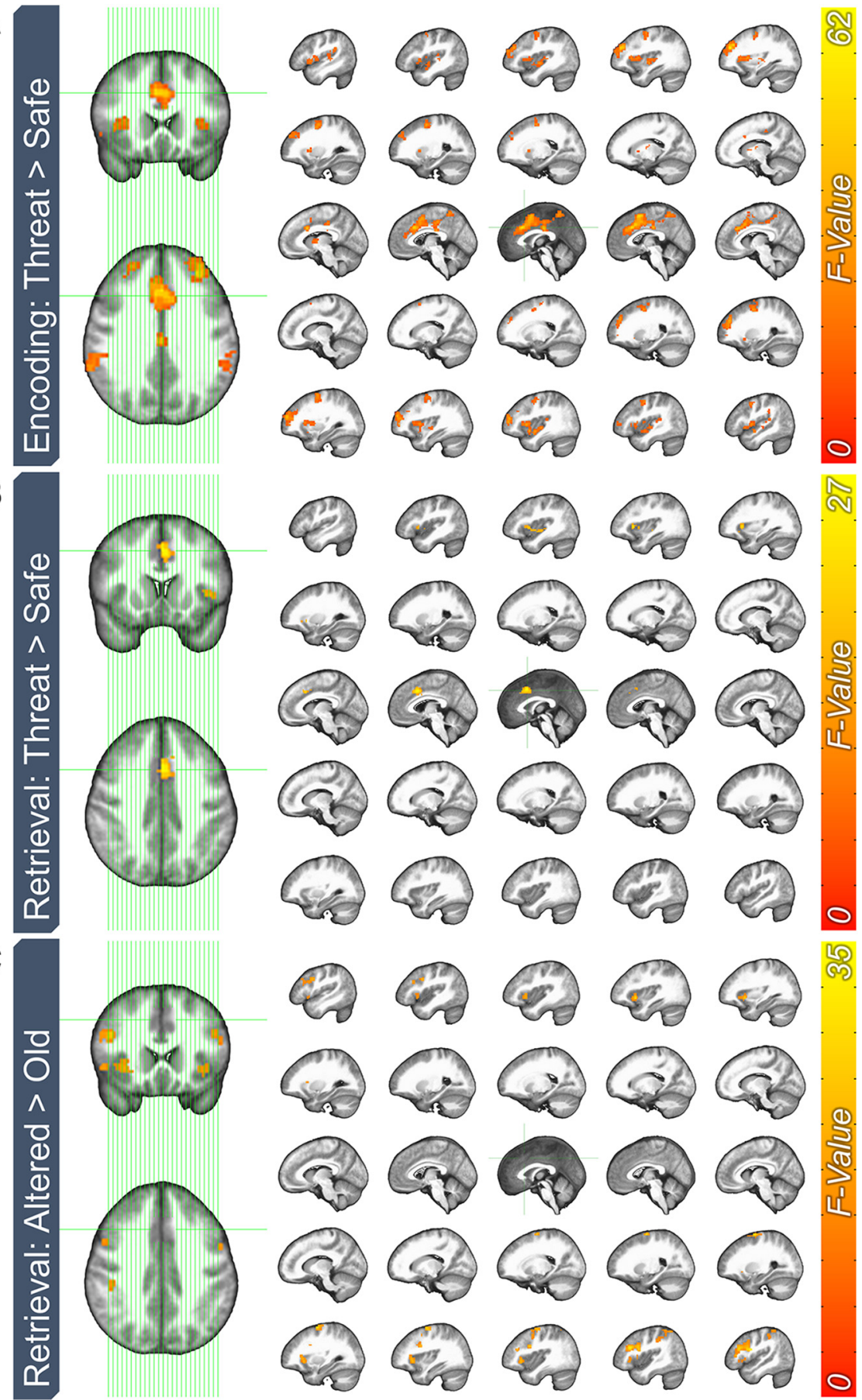

Figure 3. Whole-brain BOLD effects of threat and item type for the encoding and retrieval phases. $A$, Effect of threat on BOLD responses to items during the encoding phase. $\boldsymbol{B}$, Effect of threat on BOLD responses to items during the encoding phase. $C$, Effect of item type on BOLD responses during the retrieval phase. censored (i.e., scrubbed) TRs where the Euclidean norm of the motion parameters exceeded $0.5 \mathrm{~mm}$ and excluded subjects whose censor count exceeded $10 \%$ of the total number of TRs (Balderston et al., 2017b). The resulting $\beta$ images were then distortion corrected, coregistered with the T1 images, warped to MNI space, masked with a group-level gray matter mask, and blurred within the mask using a $6 \mathrm{~mm}$ Gaussian kernel.

Experimental design and $\mathrm{fMRI}$ analysis We analyzed the voxelwise BOLD data for encoding and retrieval separately. For encoding, we conducted a 2 (encoding condition: safe vs threat) $\times 2$ ([subsequent] retrieval condition: safe vs threat) repeated-measures ANOVA. Note that the retrieval condition factor should not affect the BOLD data during encoding and is included to ensure that the pictures are well matched across conditions. For retrieval, we conducted a 2 (encoding condition: safe vs threat) $\times 2$ (retrieval condition: safe vs threat) $\times 2$ (item: old vs altered) repeatedmeasures ANOVA. All initial analyses were performed at the voxel level across the entire brain. Simple effects for interactions were probed at the cluster level using the mean voxel intensity for each cluster that survived correction (including the dlPFC). Follow-up analyses were performed on BOLD activity within the hippocampus defined anatomically for each subject based on the freesurfer segmentation.

We used a cluster-based approach to correct for multiple comparisons. To identify a minimum cluster size, we conducted 10,000 Monte Carlo simulations using the AFNI program 3dclustsim. We used a spatial autocorrelation function with a Gaussian plus monoexponential form to account for the nonGaussian distribution of fMRI noise (Cox et al., 2017). We then thresholded the fMRI data using a voxelwise $p$-value threshold of $p<0.001$ and a minimum cluster size of $k=65$, which corresponds to a cluster-level $\alpha$ of $p<0.05$.

\section{Results}

\section{Questionnaire data}

As a manipulation check, we examined the effect of threat on subjects' retrospective affect ratings. As expected, subjects reported significantly more anxiety $\left(t_{(31)}=9.77 ; p<0.001 ; \mathrm{d}=1.73\right)$ and fear $\left(t_{(31)}=6.63 ; p<0.001 ; \mathrm{d}=1.17\right)$ and less happiness $\left(t_{(31)}=-7 ; p<0.001 ; \mathrm{d}=\right.$ $-1.24)$ in the threat blocks than in the safe blocks (Table 1).
This first level GLM included separate regressors of interest for each trial type for encoding and retrieval based on the encoding and retrieval contexts and the status of the image. For encoding, this resulted in the following trial types (Encoding/Retrieval): Safe/Safe, Safe/Threat, Threat/Safe, and Threat/Threat. For retrieval, this resulted in the following trial types (status encoding/retrieval): (new: [not presented during encoding]/safe, [not presented during encoding]/threat), (old: safe/safe, safe/threat, threat/safe, and threat/threat), and (altered: safe/safe, safe/ threat, threat/safe, and threat/threat). We also included regressors of no interest corresponding to the six motion parameters, baseline drift (fourth order polynomial), button presses, and shock trials. Finally, we

\section{Accuracy}

Next, we assessed the effect of condition during encoding and retrieval on accuracy for old and altered items using a 2 (encoding: safe vs threat) $\times 2$ (retrieval: safe vs threat) $\times 2$ (item: old vs altered) repeated-measures ANOVA (Fig. 2A). We found that subjects were more accurate identifying old items than altered items (item: $\left.F_{(1,31)}=104.61 ; p<0.001\right)$. In addition, we found that this effect was dependent on encoding condition (encoding $\times$ item interaction: $\left.F_{(1,31)}=4.68 ; p=0.04\right)$. To characterize 
this interaction, we conducted two paired-sample $t$ tests contrasting the effect of encoding condition on accuracy for the old and altered items separately. We found that, for old items, subjects were more accurate when the items were encoded in the threat blocks $\left(t_{(31)}=2.66 ; p=0.01 ; \mathrm{d}=0.47\right)$. In contrast, for altered items, accuracy was similar for items encoded in the safe and threat conditions $(p>0.05)$.

\section{Reaction time}

As with accuracy, we assessed the effect of condition during encoding and retrieval on reaction time for correct old and altered items using a 2 (encoding: safe vs threat) $\times 2$ (retrieval: safe vs threat) $\times 2$ (item: old vs altered) repeated-measures ANOVA (Fig. 2B). As with accuracy, subjects were faster for items encoded during threat blocks than during safe blocks $\left(F_{(1,31)}=4.77 ; p=\right.$ $0.04)$. In addition, there was a significant 3-way interaction $\left(F_{(1,31)}=5.49 ; p=0.03\right)$.

To probe this interaction, we began by conducting two, 2 (retrieval: safe vs threat) $\times 2$ (item: old vs altered) repeatedmeasures ANOVAs for items encoded during either the safe or threat blocks. For items encoded during the safe blocks, there was a significant 2-way interaction $\left(F_{(1,31)}=7.99 ; p=0.01\right)$; however, this was not significant for items encoded during the threat blocks $(p<0.05)$. To characterize this interaction, we conducted two paired-sample $t$ tests contrasting reaction time for old and altered items for the safe and threat retrieval blocks. When items were retrieved in safe blocks, reaction time was similar for old and altered images $(p>0.05)$; however, when items were retrieved in threat blocks, subjects were faster for old compared with altered items $\left(t_{(31)}=2.82 ; p=0.01 ; \mathrm{d}=0.5\right)$.

\section{Encoding BOLD}

We used a 2 (encoding context: safe vs threat) $\times 2$ ([subsequent] retrieval context: safe vs threat) repeated-measures ANOVA to analyze the encoding phase responses. This analysis had two purposes. The first was to determine the effectiveness of the threat manipulation during this phase by contrasting BOLD responses to images presented in the safe and threat periods. The second purpose was to determine whether the (randomly selected) items to be presented in the safe and threat blocks in the retrieval conditions evoked different patterns of activity. Note that this was a control comparison to demonstrate that, before retrieval, items did not evoke different patterns of neural activity. As expected, this $2 \times 2$ analysis yielded significant activations in several regions of the canonical fear network [e.g., anterior insula, dorsal anterior cingulate cortex (dACC); Fullana et al., 2016] as a function of encoding context, but no significant activations as a function of retrieval context and no interactions (Fig. 3A, Table 2).

\section{Retrieval BOLD}

We used a 2 (encoding condition: safe vs threat) $\times 2$ (retrieval condition: safe vs threat) $\times 2$ (item: old vs altered) repeatedmeasures ANOVA to analyze the retrieval phase responses. This analysis had four purposes. The first was to determine whether encoding condition affected BOLD responses to items during retrieval. As with encoding, the second purpose was to determine the effectiveness of the threat manipulation during this phase by contrasting BOLD responses aginst images presented in the safe and threat periods. The third purpose was to determine the effect of item type on BOLD responses. The final, and primary, purpose was to determine whether these effects were different for the old and altered items.
Table 2. Results from voxelwise analysis

\begin{tabular}{|c|c|c|c|c|c|c|}
\hline Label & Volume & $F$ & $e t a^{2}$ & $\begin{array}{l}\text { Peak a } \\
\text { (LPI) }\end{array}$ & tivation & \\
\hline \multicolumn{7}{|l|}{ Encoding: safe vs threat } \\
\hline $\mathrm{dACC}$ & 835 & 62.21 & 0.056 & 6 & 18 & 36 \\
\hline Right anterior insula & 683 & 57.76 & 0.049 & 51 & 3 & 6 \\
\hline Left posterior insula & 671 & 46.03 & 0.049 & -63 & -36 & 18 \\
\hline Right dIPFC & 267 & 40.22 & 0.049 & 33 & 57 & 18 \\
\hline Left dIPFC & 224 & 54.18 & 0.055 & -33 & 45 & 27 \\
\hline Right middle frontal gyrus & 207 & 28.76 & 0.036 & 24 & 0 & 51 \\
\hline Left precentral gyrus & 142 & 30.55 & 0.028 & -27 & -6 & 57 \\
\hline \multicolumn{7}{|l|}{ Retrieval: safe vs threat } \\
\hline Left anterior insula & 88 & 21.16 & 0.033 & -33 & 21 & 6 \\
\hline $\mathrm{dACC}$ & 84 & 27.13 & 0.042 & 0 & 15 & 42 \\
\hline \multicolumn{7}{|l|}{ Retrieval: old vs altered } \\
\hline Right dIPFC & 323 & 35.76 & 0.012 & 42 & 27 & 24 \\
\hline Right superior frontal gyrus & 109 & 32.68 & 0.011 & 30 & -3 & 66 \\
\hline Right anterior insula & 96 & 22.55 & 0.013 & 36 & 24 & 0 \\
\hline Left precentral gyrus & 96 & 25.45 & 0.009 & -51 & 6 & 36 \\
\hline Right inferior parietal lobule & 87 & 23.01 & 0.019 & 57 & -33 & 51 \\
\hline Left anterior insula & 71 & 27.72 & 0.014 & -36 & 15 & -6 \\
\hline
\end{tabular}

Retrieval: retrieval context (safe vs threat) $X$ item (old vs altered)

Right dIPFC

$\begin{array}{llllll}67 & 19.82 & 0.009 & 51 & 33 & 12\end{array}$

Related to the first purpose, there were no significant effects of encoding condition on BOLD activity to items during retrieval. In contrast, related to the second purpose, there were two significant clusters showing greater activity to items presented during the threat compared with the safe periods in the left anterior insula and dACC (Fig. 3B, Table 2). These results within the canonical fear network are also consistent with the results from encoding. Related to the third purpose, we found several significant clusters showing greater activity to altered items compared with old items. These are primarily right lateralized and located in regions of the frontoparietal attention network (Fig. 3C, Table 2).

Finally, we observed a significant retrieval by item interaction in the right dlPFC (Fig. 4). To characterize this two-way interaction, we conducted two paired-sample $t$ tests to determine the difference in responding to old and altered image as a function of retrieval condition. When items were retrieved in the safe periods, there was no difference in dlPFC activity to the old and altered images. In contrast, when items were retrieved during the threat periods, altered items evoked significantly more activity than old items $\left(t_{(31)}=6.12 ; p<0.001 ; \mathrm{d}=1.08\right)$. There were no other significant main effects or interactions.

To further explore the relationship between retrieval context and dlPFC activity to altered stimuli, we reran the single-subject GLMs using separate regressors for correct and incorrect trials and extracted the BOLD values in the dlPFC. We then conducted a 2 (encoding condition: safe vs threat) $\times 2$ (retrieval condition: safe vs threat) $\times 2$ (item: correct vs incorrect) repeated-measures ANOVA on these responses (Fig. 5). Notably, we found a significant main effect for retrieval $\left(F_{(1,31)}=5.63 ; p=0.02\right)$ and a significant retrieval context by item interaction $\left(F_{(1,31)}=4.27\right.$; $p=0.047)$. Incorrect items retrieved during threat evoked significantly more dlPFC activity than incorrect items retrieved during safety $\left(t_{(31)}=3.54 ; p<0.001\right)$, whereas correct items evoked similar levels of dlPFC activity whether they were received during periods of threat or safety $(p>0.05)$. This suggests that the increased dlPFC activity to altered items retrieved during threat was driven by an increase in responding to the incorrect items. 

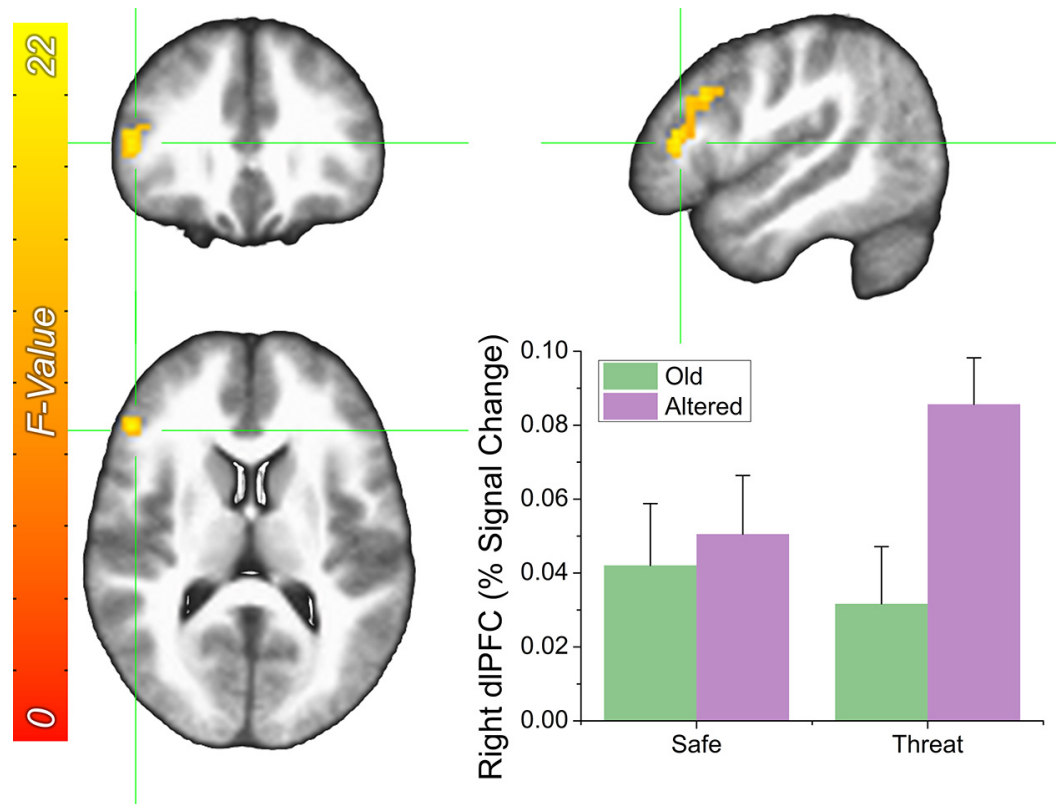

Figure 4. Effect of threat during retrieval and item type on BOLD responses in the dLPFC. Error bars indicate mean \pm SEM.
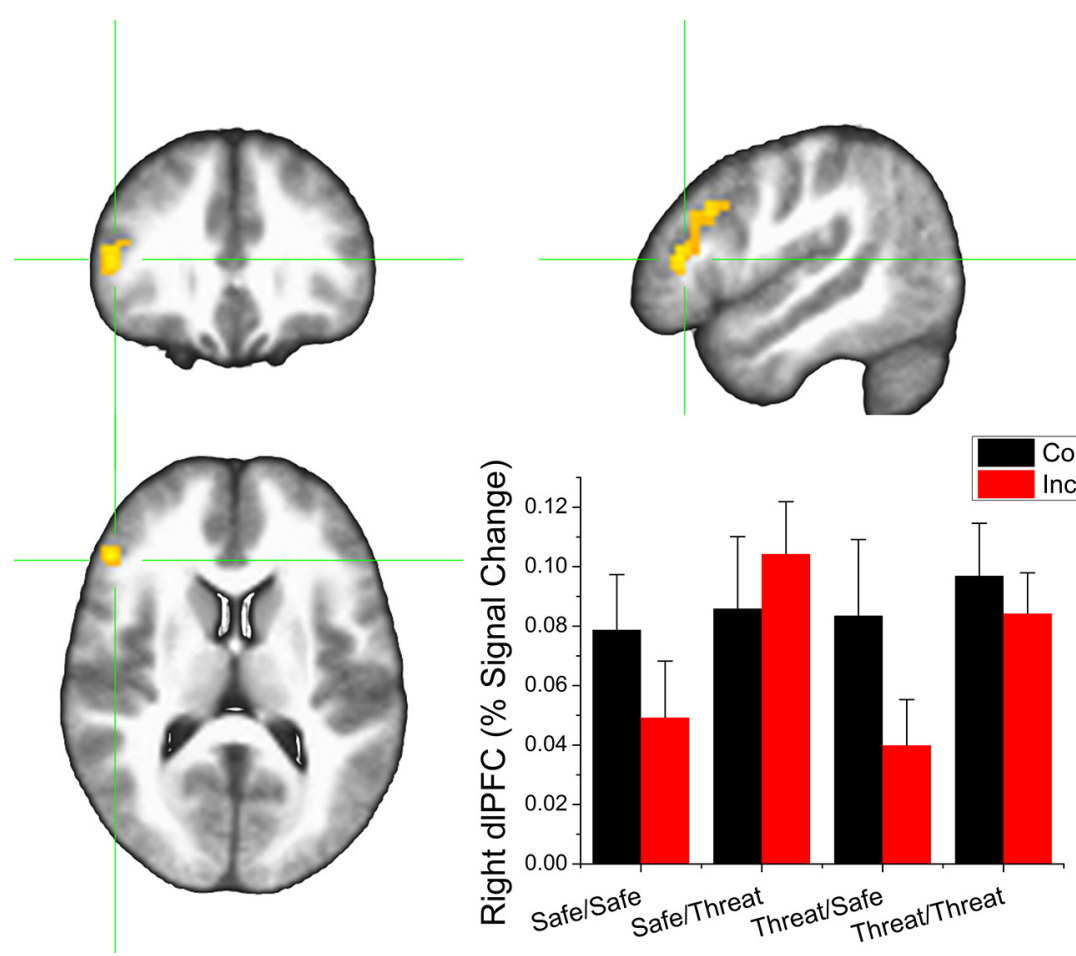

Figure 5. BOLD responses to correct and incorrect items during retrieval in the dIPFC. ROI represents the dIPFC cluster from the main analysis in Figure 4. Error bars indicate mean \pm SEM.

\section{dlPFC accuracy correlations}

Given the role of the dlPFC in both cognitive control (Braver et al., 2010; Cole et al., 2012; Cieslik et al., 2013; Harding et al., 2015) and anxiety (Basten et al., 2012; Peers et al., 2013), we probed the correlation between dlPFC and accuracy based on retrieval condition and item type. Note that this analysis is not circular with reference to the above reported interaction because the correlations are done within the 4 cells of the $2 \times 2$ interaction reported above, rather than across cells. For items retrieved during safe periods, we found no significant correlations between dlPFC ac- tivity and accuracy (Fig. $6 A ; p>0.05$ ). In contrast, when items were retrieved during the threat periods, there was a significant correlation between dlPFC activity and accuracy for altered $\left(r_{(31)}=0.56 ; p<\right.$ $0.001)$, but not old $\left(r_{(31)}=-0.01 ; p=\right.$ 0.96 ) items (Fig. $6 B$ ). In addition, the difference between the correlation coefficients was statistically significant for the old and altered items retrieved during threat periods $\left(z_{(31)}=-2.82 ; p=0.005\right)$.

Given that there was a significant interaction between retrieval context and item (correct vs incorrect) in the previous analysis, this raises the question of whether the dlPFC/accuracy correlations in the original analysis was driven by dlPFC responding to the incorrect items. If so, then we would expect that the correlation would no longer be significant when considering correct trials only. To test this, we reran the correlations between accuracy and dlPFC activity for old and altered items as a function of both retrieval context and response type (correct vs incorrect; Fig. 7). As can be seen in Figure 7 , the previously observed correlation between accuracy for altered items retrieved during threat and dlPFC activity to these same items remains significant when considering either correct $\left(r_{(31)}=\right.$ $0.62 ; p>0.001)$ or incorrect $\left(r_{(31)}=0.38\right.$; $p=0.032$ ) altered items. This is important because, by showing similar accuracy/dlPFC activity correlations for activity evoked by correct and incorrect trials, we show that the accuracy/dlPFC activity correlations reported above are not an artifact of different levels of activity for correct and incorrect trials. In addition, neither of the other correlations are significant $(p<0.05)$, which is consistent with the results above. Together, these results support the conclusion that individuals who are better able to recruit the dlPFC are better able to perform the task during periods of threat.

\section{Hippocampal subfield involvement in pattern separation}

Because we did not observe any significant effects of encoding or retrieval condition on hippocampal pattern separation using a whole-brain voxelwise approach, we decided to probe these relationships within specific subfields of the hippocampus. Accordingly, we segmented the hippocampus for each subject using Freesurfer (version 6.0) and extracted the volumes corresponding to the CA1, CA3, and dentate gyrus for each subject.

Although we used standard-resolution fMRI, which may not be optimal to differentiate functionally between hippocampal 
subfields, we took several steps to ensure as accurate a T1-EPI coregistration as possible. First, we used a reverse-phase encoded EPI blip to reduce EPI distortion in the phase-encoding direction (Hong et al., 2015). Second, we used nonlinear registration to align the T1 and EPI data to ensure precise coregistration. Third, we used unblurred EPI data to maintain the intrinsic smoothness of the EPI data and reduce cross-contamination from the subfield ROIs.

We then sampled the BOLD activity during retrieval using these ROIs and conducted a 2 (encoding condition: safe vs threat) $\times 2$ (retrieval condition: safe vs threat) $\times 2$ (item: old vs altered) repeated-measures ANOVA on the BOLD responses in the CA1, CA3, and dentate gyrus. We found a significant main effect for retrieval in the CA3 region $\left(F_{(1,31)}=\right.$ 5.95; $p=0.02$ ), with greater deactivation for altered items compared with old, but no other main effects or interactions (Fig. 8).

In addition, because previous pattern separation studies have shown that the hippocampus (specifically CA3 and the dentate gyrus) is more involved in successful pattern separation versus unsuccessful pattern separation trials (Kirwan and Stark, 2007), we examined the effect of encoding and retrieval condition on activity in CA1, CA3, and the dentate gyrus for correct versus incorrect responses to altered stimuli using a 2 (encoding condition: safe vs threat) $\times 2$ (retrieval condition: safe vs threat) $\times 2$ (item: correct vs incorrect) repeated-measures ANOVA on the $\mathrm{BOLD}$ responses in the CA1, CA3, and dentate gyrus. Consistent with previous work (Kirwan and Stark, 2007), we found significantly greater deactivation in all three regions to correctly versus incorrectly recalled altered items (CA1: $F_{(1,31)}=6.35$; $p=0.017$, CA3: $F_{(1,31)}=8.61 ; p<0.001$, dentate gyrus: $\left.F_{(1,31)}=8.85 ; p<0.001\right)$, but no other main effects or interactions (Fig. 9).

\section{Discussion}

The purpose of this study was to examine the effect of anxiety during encoding and retrieval on neural activity during BPS. We predicted differences in activity to altered versus old items in the hippocampus and dlPFC as a function of encoding and retrieval condition. Although we found no significant effects of condition in the hippocampus, we found that dlPFC activity to altered items was increased significantly when these items were retrieved under threat and that this increase was due in part to an increase in dlPFC activity to incorrect items. In addition, we found that dlPFC activity across subjects was correlated with performance for altered items independently of whether they were recalled correctly or incorrectly. Together, these results suggest that dlPFC activity may facilitate the ability to identify the altered
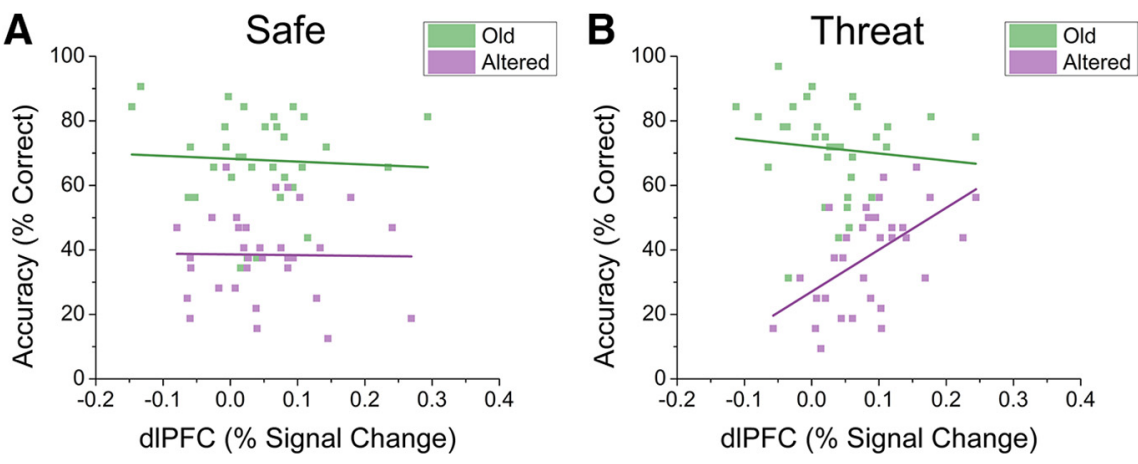

Figure 6. Scatter plots examining correlations between accuracy and dIPFC activity during the retrieval phase. $\boldsymbol{A}$, Correlations or old and altered items presented during periods of safety during retrieval. $\boldsymbol{B}$, Correlations for old and altered items presented

\section{A}
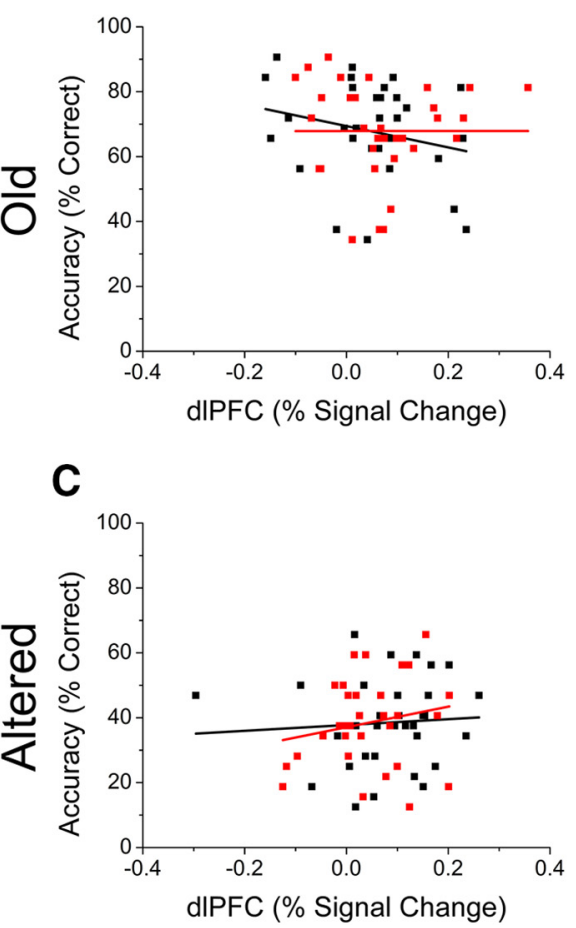
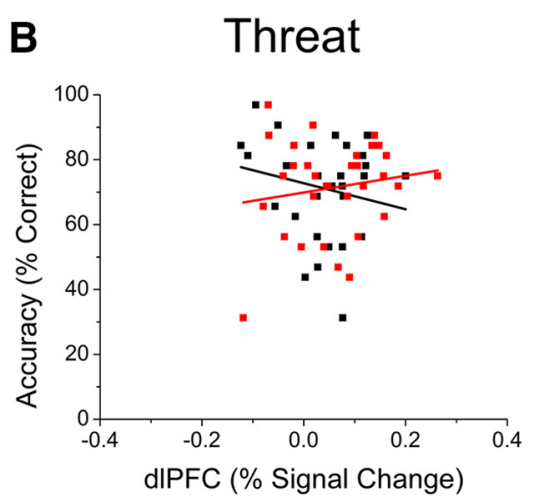

D

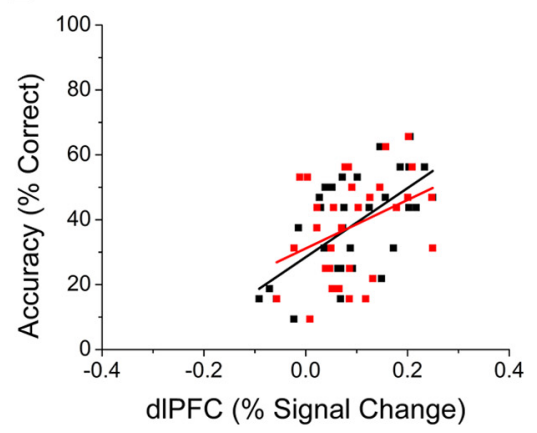

Figure 7. Correlations between accuracy and dIPFC activity during retrieval for correctly and incorrectly identified old $(\boldsymbol{A}, \boldsymbol{B})$ and altered $(\boldsymbol{C}, \boldsymbol{D})$ items during the safe $(\boldsymbol{B}, \boldsymbol{D})$ and threat $(\boldsymbol{B}, \boldsymbol{D})$ conditions. Black squares and items represent correct items and red squares and lines represent incorrect items.

stimuli during threat (Balderston et al., 2017a). More broadly, these results may provide support for a mechanistic explanation of fear overgeneralization in anxiety and PTSD and may provide a framework for future studies in these clinical populations, which is discussed below.

Counter to our first hypothesis, we failed to find any effect of encoding or retrieval condition on hippocampal activity to items during retrieval. It is well known that the hippocampus is important for memory encoding (Treves et al., 1994; O'Reilly and Norman, 2002) and BPS (Rolls and Kesner, 2006; Sahay et al., 2011a; Rolls, 2013a) and BPS specifically relies on CA3 and the dentate gyrus (Leutgeb et al., 2007; Leal et al., 2014). However, when we analyzed activity within hippocampal subfields, we found a significant effect of item type (old vs altered) on CA3 activity. In addition, we found that correctly recalled altered items evoked larger magnitude deactivations in the CA1, CA3, and dentate 
A
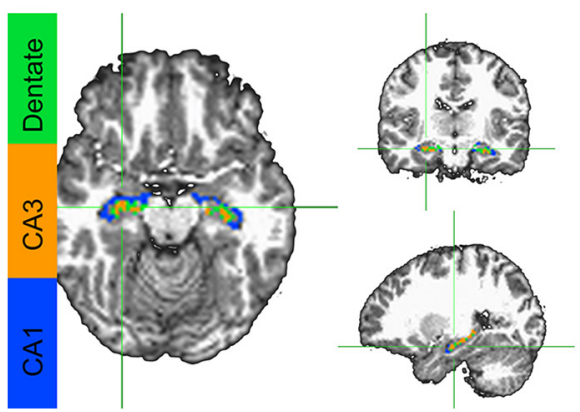

B

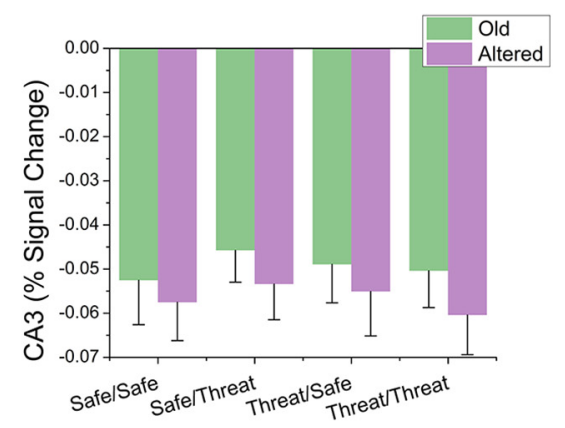

Figure 8. BOLD responses to old and altered items during retrieval in the CA3 region of the hippocampus. $A, R 0$ ls represent the extent of the $C A 3$ region (orange) in an example subject. $B$, Percent signal change in CA 3 evoked by 0 ld and Altered items. Error bars indicate mean \pm SEM.

gyrus. These findings replicate previous BPS results (Kirwan and Stark, 2007) and suggest that our null result is not due to an inability to recover signal from the hippocampus. However, we used standard-resolution fMRI, which may not be sensitive to differences in subfield activation within the hippocampus (Azab et al., 2014; Reagh and Yassa, 2014; Reagh et al., 2014; Stokes et al., 2015; Suthana et al., 2015; Berron et al., 2016). Accordingly, the current hippocampal results should be interpreted with caution and future work with high-resolution fMRI should be done exploring the effect of threat on hippocampal subfield activation during BPS. In addition, given that hippocampal activity can be linked to subsequent memory performance (Shrager et al., 2008; Park and Rugg, 2010), these studies should examine hippocampal subfield activity during both encoding and retrieval separated by performance during the retrieval session.

BPS involves separate encoding and retrieval phases (Stark et al., 2013; van Hagen et al., 2015) and, given that the purpose of this work was to probe activity during retrieval, it is possible that we missed a subtle effect of threat on hippocampal activity during encoding. Although preliminary analyses did not reveal any effect of threat on hippocampal activity during encoding, subjects in the current study were more accurate for old items encoded during threat compared with those encoded during safety. However, given that this effect was not observed for altered items, we believe that this finding is unrelated to pattern separation, reflecting instead a facilitation of memory encoding. In fact, previous work suggests that emotion enhances memory encoding (Clark et al., 1983; Eich, 1995; Cahill et al., 1996; Canli et al., 2000; McGaugh, 2002, 2004; Kogan and Richter-Levin, 2010) and that this effect can be traced to noradrenergic inputs to the hippocampus from the basal forebrain, which are a consequence of amygdala activation (Walling et al., 2004; Segal and Cahill, 2009; Segal et al., 2012; Hansen and Manahan-Vaughan, 2015). Given that multiple lines of evidence suggest that the hippocampus is primarily involved in memory encoding rather than retrieval (McClelland et al., 1995; Squire and Bayley, 2007; Squire, 2009; Squire and Wixted, 2011), future work should be conducted to further explore the relationship between induced anxiety during encoding and hippocampal activity.

In contrast, our dlPFC findings were with altered images. Among that image category, we found that successful retrieval during threat was associated with increased dlPFC activity. These results suggest that the key interaction between anxiety and pattern separation occurs during retrieval and that the dlPFC during retrieval may be an important factor. However, given that, with subjects, correct and incorrect trials were associated with similar levels of dlPFC activation indicates that dlPFC was necessary for successful overall performance, but not sufficient to prevent all types of errors. Much is known about the dlPFC and cognitive control (Braver et al., 2010; Cole et al., 2012; Cieslik et al., 2013; Harding et al., 2015). It is known to support both working memory (Carlson et al., 1998; Owen et al., 2005; León-Domínguez et al., 2015) and attention (Grimault et al., 2009; Warren et al., 2013), both of which are important for goal maintenance (Koechlin and Summerfield, 2007). For instance, single neurons in the dlPFC exhibit persistent firing during white matter (WM) maintenance intervals (Curtis and D'Esposito, 2003; Sreenivasan et al., 2014), dlPFC activity increases as WM load increases (Carlson et al., 1998; Owen et al., 2005), and the dlPFC can filter out distracting information during difficult cognitive tasks (Tang et al., 2016). Together, these findings suggest that the role of the dlPFC in WM is to maintain goal representations across time and to filter out distracting information that may interfere with performance. The degree to which this filter is effective is based on two factors, the integrity of the filter (i.e., attentional control; Eysenck et al., 2007) and the salience of the to-be-filtered distracting information (Stout et al., 2013). Rather than competing directly with other stimuli for access to consciousness, we believe that threat increases the salience of other to-be-ignored stimuli. It is important that altered items were more difficult to identify correctly than old items, which is consistent with our previous findings (Balderston et al., 2017a). Accordingly, we believe that this increase in difficulty, combined with the distraction of the threat-related anxiety, triggered an increase in dlPFC activity for the altered items retrieved under threat. In addition, this increase in activity was correlated with performance across subjects, suggesting that it was indeed beneficial. Together, these results suggest that the dIPFC may compensate for the anxiety-induced cognitive deficits that affect difficult cognitive tasks such as stimulus generalization (Cole et al., 2014). Interestingly, this interpretation raises the testable hypothesis that anxious individuals, who are less able to recruit dlPFC activity (Balderston et al., 2017b), may show reduced accuracy for altered items during threat.

This hypothesis is consistent with the attentional control theory of anxiety, which suggests that individuals with anxiety disorders are less able to control their attention (Armstrong et al., 2011; Price et al., 2011; Najmi et al., 2012, 2014; ReinholdtDunne et al., 2013; Berggren and Derakshan, 2013a, 2013b). According to this hypothesis, overgeneralization in anxious patients may be related to poor attention control, which is mediated by a reduced ability to recruit the dIPFC rather than impaired BPS per se (Balderston et al., 2017a). Indeed, individuals with PTSD show reduced dlPFC generalization gradients to visual cues that resemble feared stimuli (Kaczkurkin et al., 2017). Finally, they provide a mechanistic explanation for this overgeneralization, suggesting that it arises from deficits in recruiting the dlPFC during periods in which discrimination is difficult (Basten et al., 2012; Peers et al., 2013). These results are consistent with previous findings that anxiety patients are less able to recruit the dlPFC when high demands are placed on WM (Shackman et al., 2009; Balderston et al., 2017b), that increasing demands on WM reduce anxiety 
A

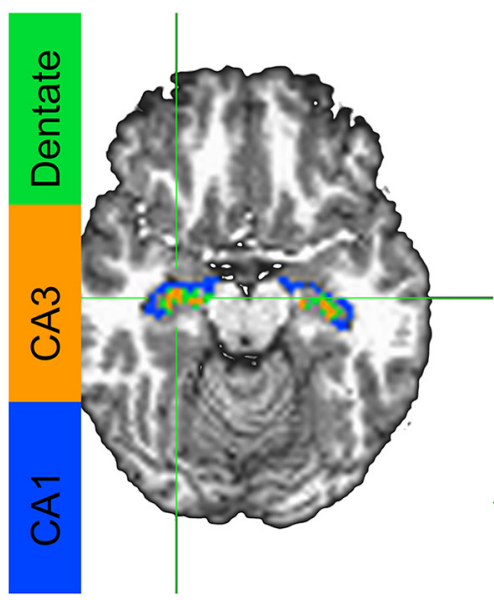

B

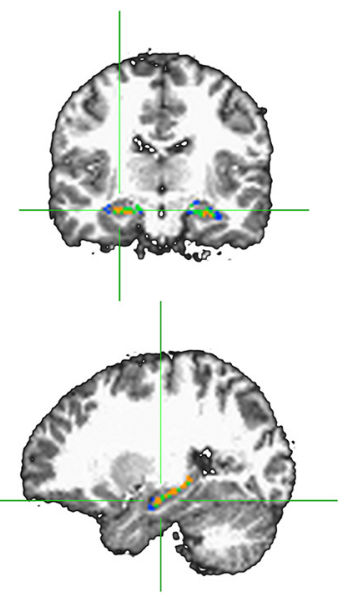

c Dentate Gyrus

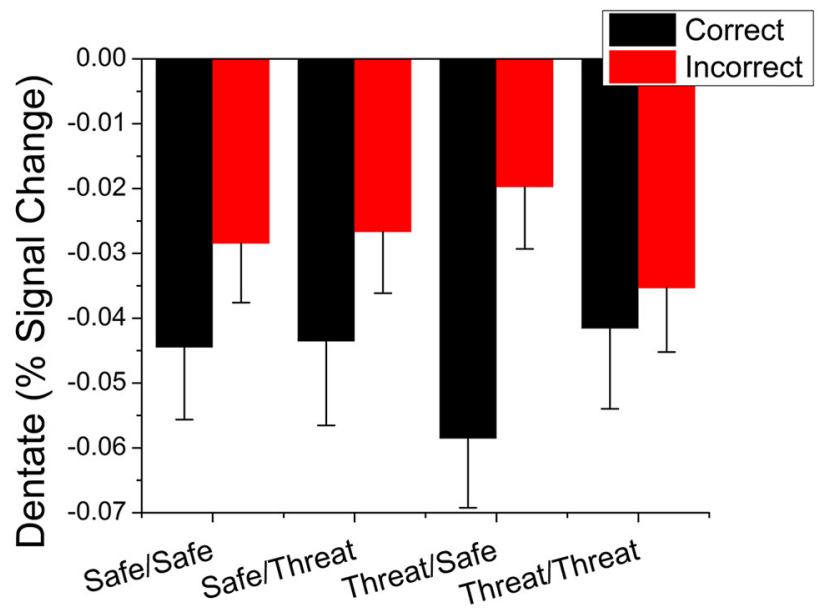

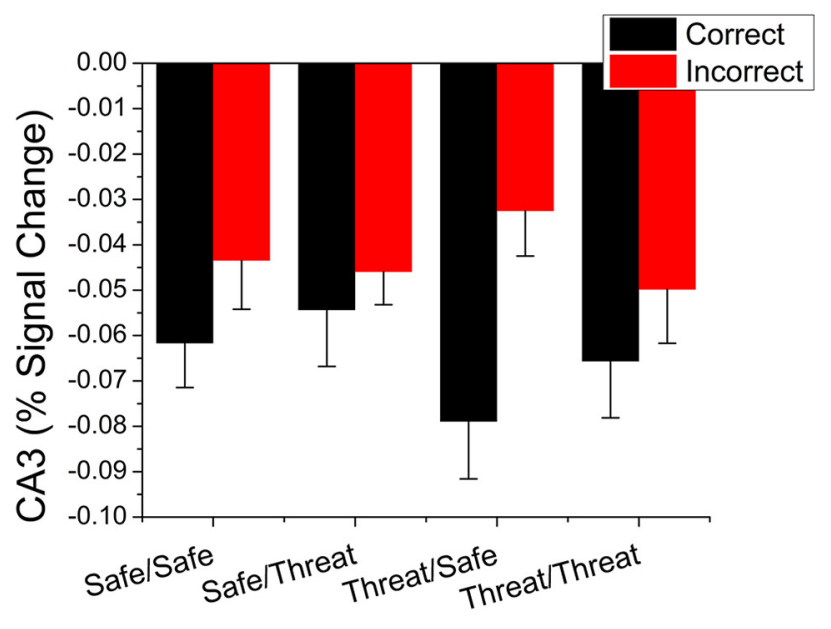

D

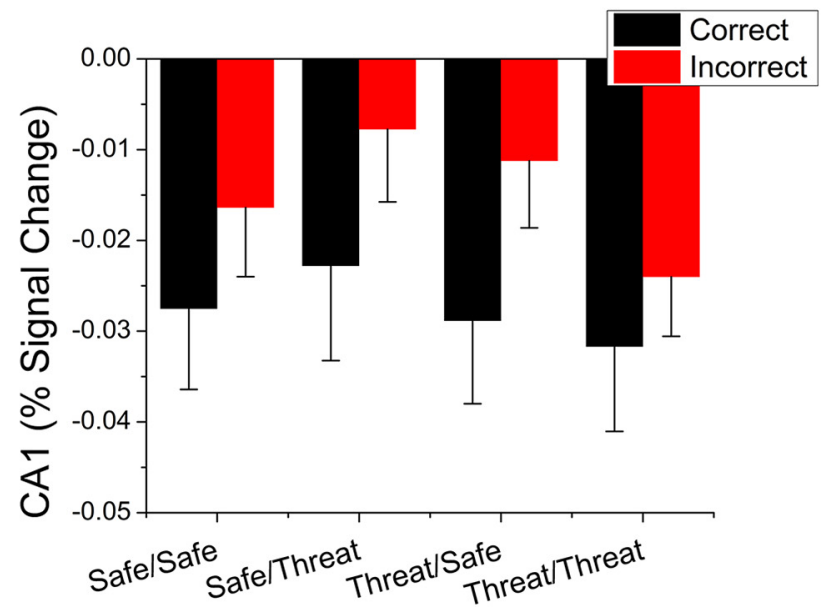

Figure 9. BOLD responses to correct and incorrect altered items during retrieval in the $C A 3(\boldsymbol{B})$, dentate gyrus $(\boldsymbol{C})$, and $C A 1(\boldsymbol{D}) . \boldsymbol{A}, \mathrm{R} 0 \mathrm{ls}$ represent the extent of each subregion in an example subject. $B-D$, Bars represent percent signal change evoked by correct and incorrect trials. Error bars indicate mean $\pm S E M$.

(Vytal et al., 2012, 2013; Balderston et al., 2016), and that dlPFC activity is negatively correlated with anxiety during periods of unpredictable shock (Ironside et al., 2016). Future studies should be conducted to test this hypothesis in patient populations.

Importantly, these results may have implications for treatment. If the dlPFC turns out to be involved in overgeneralization in anxious patients, then this structure could be targeted for treatment with neuromodulation (Slotema et al., 2010). The dlPFC is cortical and can therefore be targeted with transcranial magnetic stimulation and transcranial direct current stimulation (Balconi and Vitaloni, 2012; Bogdanov and Schwabe, 2016; Ironside et al., 2016). Indeed, this area is a target for other psychiatric disorders and has received U.S. Food and Drug Administration approval for the treatment of depression (Horvath et al., 2010). However, unlike depression, in which treatments typically attempt to increase activity in the left dlPFC and decrease activity in the right dlPFC (Shajahan et al., 2002; Miniussi et al., 2005; O'Reardon et al., 2007; Stern et al., 2007; Horvath et al., 2010; Nauczyciel et al., 2011; Fox et al., 2012; Chen et al., 2013; Lefaucheur et al., 2014; Concerto et al., 2015), our results suggest that treatments should attempt to increase rather than decrease activity in the right dlPFC, which is consistent with our previous data (Balderston et al., 2017b).

\section{Conclusions}

We studied the effect of anxiety on neural activity during BPS and found that the dlPFC is engaged when identifying altered items during periods of threat. These results suggest that the dIPFC may be important for overcoming the distraction of threat processing to enable the identification of subtle differences in items or contexts to facilitate discrimination. Importantly, anxiety and PTSD patients show deficits in attentional control (Armstrong et al., 2011; Price et al., 2011; Najmi et al., 2012, 2014; ReinholdtDunne et al., 2013; Berggren and Derakshan, 2013a, 2013b) and an inability to recruit the dlPFC during difficult cognitive tasks (Shackman et al., 2009; Balderston et al., 2017b) and stimulus generalization (Kaczkurkin et al., 2017), pointing to attentional control deficit as a potential mechanism for overgeneralization (Levy-Gigi et al., 2012, 2015; Greenberg et al., 2013; Lissek et al., 2014; Kostek et al., 2014; van Meurs et al., 2014; Anastasides et al., 
2015; Laufer et al., 2016). According to this model, it should be possible to treat this overgeneralization using noninvasive neuromodulation techniques targeting the dIPFC (Slotema et al., 2010).

\section{References}

American Psychiatric Association (2013) Diagnostic and Statistical Manual of Mental Disorders: Dsm-5. Arlington, VA: American Psychiatric Publishers.

Anastasides N, Beck KD, Pang KC, Servatius RJ, Gilbertson MW, Orr SP, Myers CE (2015) Increased generalization of learned associations is related to re-experiencing symptoms in veterans with symptoms of posttraumatic stress. Stress 18:484-489. CrossRef Medline

Armstrong T, Zald DH, Olatunji BO (2011) Attentional control in OCD and GAD: specificity and associations with core cognitive symptoms. Behav Res Ther 49:756-762. CrossRef Medline

Azab M, Stark SM, Stark CE (2014) Contributions of human hippocampal subfields to spatial and temporal pattern separation. Hippocampus 24: 293-302. CrossRef Medline

Balconi M, Vitaloni S (2012) The tDCS effect on alpha brain oscillation for correct vs. incorrect object use: the contribution of the left DLPFC. Neurosci Lett 517:25-29. CrossRef Medline

Balderston NL, Quispe-Escudero D, Hale E, Davis A, O'Connell K, Ernst M, Grillon C (2016) Working memory maintenance is sufficient to reduce state anxiety. Psychophysiology 53:1660-1668. CrossRef Medline

Balderston NL, Mathur A, Adu-Brimpong J, Hale EA, Ernst M, Grillon C (2017a) Effect of anxiety on behavioural pattern separation in humans. Cogn Emot 31:238-248. Medline

Balderston NL, Vytal KE, O'Connell K, Torrisi S, Letkiewicz A, Ernst M, Grillon C (2017b) Anxiety patients show reduced working memory related dlPFC activation during safety and threat. Depress Anxiety 34:2536. CrossRef Medline

Barbey AK, Koenigs M, Grafman J (2013) Dorsolateral prefrontal contributions to human working memory. Cortex 49:1195-1205. CrossRef Medline

Basten U, Stelzel C, Fiebach CJ (2012) Trait anxiety and the neural efficiency of manipulation in working memory. Cogn Affect Behav Neurosci 12: 571-588. CrossRef Medline

Berggren N, Derakshan N (2013a) The role of consciousness in attentional control differences in trait anxiety. Cogn Emot 27:923-931. CrossRef Medline

Berggren N, Derakshan N (2013b) Attentional control deficits in trait anxiety: why you see them and why you don't. Biol Psychol 92:440446. CrossRef Medline

Berron D, Schütze H, Maass A, Cardenas-Blanco A, Kuijf HJ, Kumaran D, DüzelE (2016) Strong evidence for pattern separation in human dentate gyrus. J Neurosci 36:7569-7579. CrossRef Medline

Bogdanov M, Schwabe L (2016) Transcranial stimulation of the dorsolateral prefrontal cortex prevents stress-induced working memory deficits. J Neurosci 36:1429-1437. CrossRef Medline

Braver TS, Cole MW, Yarkoni T (2010) Vive les differences! Individual variation in neural mechanisms of executive control. Curr Opin Neurobiol 20:242-250. CrossRef Medline

Cahill L, Haier RJ, Fallon J, Alkire MT, Tang C, Keator D, Wu J, McGaugh JL (1996) Amygdala activity at encoding correlated with long-term, free recall of emotional information. Proc Natl Acad Sci U S A 93:8016-8021. CrossRef Medline

Canli T, Zhao Z, Brewer J, Gabrieli JD, Cahill L (2000) Event-related activation in the human amygdala associates with later memory for individual emotional experience. J Neurosci 20:RC99. Medline

Carlson S, Martinkauppi S, Rämä P, Salli E, Korvenoja A, Aronen HJ (1998) Distribution of cortical activation during visuospatial n-back tasks as revealed by functional magnetic resonance imaging. Cereb Cortex 8:743752. CrossRef Medline

Cha J, Greenberg T, Carlson JM, Dedora DJ, Hajcak G, Mujica-Parodi LR (2014) Circuit-wide structural and functional measures predict ventromedial prefrontal cortex fear generalization: implications for generalized anxiety disorder. J Neurosci 34:4043-4053. CrossRef Medline

Chen J, Zhou C, Wu B, Wang Y, Li Q, Wei Y, Yang D, Mu J, Zhu D, Zou D, Xie $P$ (2013) Left versus right repetitive transcranial magnetic stimulation in treating major depression: a meta-analysis of randomised controlled trials. Psychiatry Res 210:1260-1264. CrossRef Medline

Cieslik EC, Zilles K, Caspers S, Roski C, Kellermann TS, Jakobs O, Langner R,
Laird AR, Fox PT, Eickhoff SB (2013) Is there one DLPFC in cognitive action control? Evidence for heterogeneity from co-activation-based parcellation. Cereb Cortex 23:2677-2689. CrossRef Medline

Clark MS, Milberg S, Ross J (1983) Arousal cues arousal-related material in memory: implications for understanding effects of mood on memory. J Verbal Learning Verbal Behav 22:633-649. CrossRef

Cole MW, Yarkoni T, Repovs G, Anticevic A, Braver TS (2012) Global connectivity of prefrontal cortex predicts cognitive control and intelligence. J Neurosci 32:8988-8999. CrossRef Medline

Cole MW, Repovš G, Anticevic A (2014) The frontoparietal control system: a central role in mental health. Neuroscientist 20:652-664. CrossRef Medline

Concerto C, Lanza G, Cantone M, Ferri R, Pennisi G, Bella R, Aguglia E (2015) Repetitive transcranial magnetic stimulation in patients with drug-resistant major depression: a six-month clinical follow-up study. Int J Psychiatry Clin Pract 19:252-258. CrossRef Medline

Cox RW (1996) AFNI: software for analysis and visualization of functional magnetic resonance neuroimages. Comput Biomed Res 29:162-173. CrossRef Medline

Cox RW, Chen G, Glen DR, Reynolds RC, Taylor PA (2017) FMRI clustering in AFNI: false-positive rates redux. Brain Connect 7:152-171. CrossRef Medline

Curtis CE, D'Esposito M (2003) Persistent activity in the prefrontal cortex during working memory. Trends Cogn Sci 7:415-423. CrossRef Medline

Doxey CR, Kirwan CB (2015) Structural and functional correlates of behavioral pattern separation in the hippocampus and medial temporal lobe. Hippocampus 25:524-533. CrossRef Medline

Eich E (1995) Mood as a mediator of place dependent memory. J Exp Psychol Gen 124:293-308. CrossRef Medline

Eysenck MW, Derakshan N, Santos R, Calvo MG (2007) Anxiety and cognitive performance: attentional control theory. Emotion 7:336-353. CrossRef Medline

Fischl B, Salat DH, Busa E, Albert M, Dieterich M, Haselgrove C, van der Kouwe A, Killiany R, Kennedy D, Klaveness S, Montillo A, Makris N, Rosen B, Dale AM (2002) Whole brain segmentation: automated labeling of neuroanatomical structures in the human brain. Neuron 33:341355. CrossRef Medline

Fischl B, Salat DH, van der Kouwe AJ, Makris N, Ségonne F, Quinn BT, Dale AM (2004) Sequence-independent segmentation of magnetic resonance images. Neuroimage 23:S69-S84. CrossRef Medline

Fox MD, Buckner RL, White MP, Greicius MD, Pascual-Leone A (2012) Efficacy of transcranial magnetic stimulation targets for depression is related to intrinsic functional connectivity with the subgenual cingulate. Biol Psychiatry 72:595-603. CrossRef Medline

Fullana MA, Harrison BJ, Soriano-Mas C, Vervliet B, Cardoner N, ÀvilaParcet A, Radua J (2016) Neural signatures of human fear conditioning: an updated and extended meta-analysis of fMRI studies. Mol Psychiatry 21:500-508. CrossRef Medline

Geier CF, Garver KE, Luna B (2007) Circuitry underlying temporally extended spatial working memory. Neuroimage 35:904-915. CrossRef Medline

Geusebroek JM, Burghouts GJ, Smeulders AWM (2005) The Amsterdam Library of Object Images. Int J Comput Vis 61:103-112. CrossRef

Greenberg T, Carlson JM, Cha J, Hajcak G, Mujica-Parodi LR (2013) Ventromedial prefrontal cortex reactivity is altered in generalized anxiety disorder during fear generalization. Depress Anxiety 30:242-250. CrossRef Medline

Grillon C (2008) Models and mechanisms of anxiety: Evidence from startle studies. Psychopharmacology (Berl) 199:421-437. CrossRef Medline

Grillon C, Pine DS, Lissek S, Rabin S, Bonne O, Vythilingam M (2009) Increased anxiety during anticipation of unpredictable aversive stimuli in posttraumatic stress disorder but not in generalized anxiety disorder. Biol Psychiatry 66:47-53. CrossRef Medline

Grimault S, Robitaille N, Grova C, Lina JM, Dubarry AS, Jolicoeur P (2009) Oscillatory activity in parietal and dorsolateral prefrontal cortex during retention in visual short-term memory: additive effects of spatial attention and memory load. Hum Brain Mapp 30:3378-3392. CrossRef Medline

Hansen N, Manahan-Vaughan D (2015) Locus coeruleus stimulation facilitates long-term depression in the dentate gyrus that requires activation of $\beta$-adrenergic receptors. Cereb Cortex 25:1889-1896. CrossRef Medline

Harding IH, Yücel M, Harrison BJ, Pantelis C, Breakspear M (2015) Effective connectivity within the frontoparietal control network differentiates 
cognitive control and working memory. Neuroimage 106:144-153. CrossRef Medline

Hong X, To XV, Teh I, Soh JR, Chuang KH (2015) Evaluation of EPI distortion correction methods for quantitative MRI of the brain at high magnetic field. Magn Reson Imaging 33:1098-1105. CrossRef Medline

Horvath JC, Mathews J, Demitrack M a, Pascual-Leone A (2010) The NeuroStar TMS device: conducting the FDA approved protocol for treatment of depression. J Vis Exp 45: pii: 2345. CrossRef Medline

Insel TR (2014) The NIMH research domain criteria (RDoC) project: precision medicine for psychiatry. Am J Psychiatry 171:395-397. CrossRef Medline

Ironside M, O'Shea J, Cowen PJ, Harmer CJ (2016) Frontal cortex stimulation reduces vigilance to threat: implications for the treatment of depression and anxiety. Biol Psychiatry 79:823-830. CrossRef Medline

Kaczkurkin AN, Burton PC, Chazin SM, Manbeck AB, Espensen-Sturges T, Cooper SE, Sponheim SR, Lissek S (2017) Neural substrates of overgeneralized conditioned fear in PTSD. Am J Psychiatry 174:125-134. CrossRef Medline

Kirwan CB, Stark CE (2007) Overcoming interference: an fMRI investigation of pattern separation in the medial temporal lobe. Learn Mem 14: 625-633. CrossRef Medline

Koechlin E, Summerfield C (2007) An information theoretical approach to prefrontal executive function. Trends Cogn Sci 11:229-235. CrossRef Medline

Kogan I, Richter-Levin G (2010) Emotional memory formation under lower versus higher stress conditions. Front Behav Neurosci 4:183. CrossRef Medline

Kostek JA, Beck KD, Gilbertson MW, Orr SP, Pang KC, Servatius RJ, Myers CE (2014) Acquired equivalence in veterans with symptoms of posttraumatic stress: reexperiencing symptoms are associated with greater generalization. J Trauma Stress 27:717-720. CrossRef Medline

Kundu P, Inati SJ, Evans JW, Luh WM, Bandettini PA (2012) Differentiating BOLD and non-BOLD signals in fMRI time series using multi-echo EPI. Neuroimage 60:1759-1770. CrossRef Medline

Laufer O, Israeli D, Paz R (2016) Behavioral and neural mechanisms of overgeneralization in anxiety. Curr Biol 26:713-722. CrossRef Medline

Leal SL, Tighe SK, Jones CK, Yassa MA (2014) Pattern separation of emotional information in hippocampal dentate and CA3. Hippocampus 24: 1146-1155. CrossRef Medline

Lefaucheur JP et al. (2014) Evidence-based guidelines on the therapeutic use of repetitive transcranial magnetic stimulation (rTMS). Clin Neurophysiol 125:2150-2206. CrossRef Medline

León-Domínguez U, Martín-Rodríguez JF, León-Carrión J (2015) Executive n-back tasks for the neuropsychological assessment of working memory. Behav Brain Res 292:167-173. CrossRef Medline

Leutgeb JK, Leutgeb S, Moser MB, Moser EI (2007) Pattern separation in the dentate gyrus and CA3 of the hippocampus. Science 315:961-966. CrossRef Medline

Levy-Gigi E, Kéri S, Myers CE, Lencovsky Z, Sharvit-Benbaji H, Orr SP, Gilbertson MW, Servatius RJ, Tsao JW, Gluck MA (2012) Individuals with posttraumatic stress disorder show a selective deficit in generalization of associative learning. Neuropsychology 26:758-767. CrossRef Medline

Levy-Gigi E, Szabo C, Richter-Levin G, Kéri S (2015) Reduced hippocampal volume is associated with overgeneralization of negative context in individuals with PTSD. Neuropsychology 29:151-161. CrossRef Medline

Lissek S, Kaczkurkin AN, Rabin S, Geraci M, Pine DS, Grillon C (2014) Generalized anxiety disorder is associated with overgeneralization of classically conditioned fear. Biol Psychiatry 75:909-915. CrossRef Medline

McClelland JL, McNaughton BL, O’Reilly RC (1995) Why there are complementary learning systems in the hippocampus and neocortex: insights from the successes and failures of connectionist models of learning and memory. Psychol Rev 102:419-457. CrossRef Medline

McGaugh JL (2002) Memory consolidation and the amygdala: A systems perspective. Trends Neurosci 25:456-461. CrossRef Medline

McGaugh JL (2004) The amygdala modulates the consolidation of memories of emotionally arousing experiences. Annu Rev Neurosci 27:1-28. CrossRef Medline

Miniussi C, Bonato C, Bignotti S, Gazzoli A, Gennarelli M, Pasqualetti P, Tura GB, Ventriglia M, Rossini PM (2005) Repetitive transcranial magnetic stimulation (rTMS) at high and low frequency: an efficacious therapy for major drug-resistant depression? Clin Neurophysiol 116:1062-1071. CrossRef Medline

Najmi S, Kuckertz JM, Amir N (2012) Attentional impairment in anxiety: inefficiency in expanding the scope of attention. Depress Anxiety 29:243249. CrossRef Medline

Najmi S, Amir N, Frosio KE, Ayers C (2015) The effects of cognitive load on attention control in subclinical anxiety and generalised anxiety disorder. Cogn Emot 29:1210-1223. CrossRef Medline

Nauczyciel C, Hellier P, Morandi X, Blestel S, Drapier D, Ferre JC, Barillot C, Millet B (2011) Assessment of standard coil positioning in transcranial magnetic stimulation in depression. Psychiatry Res 186:232-238. CrossRef Medline

O’Reardon JP, Solvason HB, Janicak PG, Sampson S, Isenberg KE, Nahas Z, McDonald WM, Avery D, Fitzgerald PB, Loo C, Demitrack MA, George MS, Sackeim HA (2007) Efficacy and safety of transcranial magnetic stimulation in the acute treatment of major depression: a multisite randomized controlled trial. Biol Psychiatry 62:1208-1216. CrossRef Medline

O’Reilly RC, Norman KA (2002) Hippocampal and neocortical contributions to memory: advances in the complementary learning systems framework. Trends Cogn Sci 6:505-510. CrossRef Medline

Owen AM, McMillan KM, Laird AR, Bullmore E (2005) N-back working memory paradigm: a meta-analysis of normative functional neuroimaging studies. Hum Brain Mapp 25:46-59. CrossRef Medline

Park H, Rugg MD (2010) Prestimulus hippocampal activity predicts later recollection. Hippocampus 20:24-28. CrossRef Medline

Peers PV, Simons JS, Lawrence AD (2013) Prefrontal control of attention to threat. Front Hum Neurosci 7:24. CrossRef Medline

Price RB, Eldreth DA, Mohlman J (2011) Deficient prefrontal attentional control in late-life generalized anxiety disorder: an fMRI investigation. Transl Psychiatry 1:e46. CrossRef Medline

Reagh ZM, Yassa MA (2014) Object and spatial mnemonic interference differentially engage lateral and medial entorhinal cortex in humans. Proc Natl Acad Sci U S A 111:E4264-E4273. CrossRef Medline

Reagh ZM, Watabe J, Ly M, Murray E, Yassa MA (2014) Dissociated signals in human dentate gyrus and ca3 predict different facets of recognition memory. J Neurosci 34:13301-13313. CrossRef Medline

Reinholdt-Dunne ML, Mogg K, Bradley BP (2013) Attention control: Relationships between self-report and behavioural measures, and symptoms of anxiety and depression. Cogn Emot 27:430-440. CrossRef Medline

Rolls ET (2013a) The mechanisms for pattern completion and pattern separation in the hippocampus. Front Syst Neurosci 7:74. CrossRef Medline

Rolls ET (2013b) A quantitative theory of the functions of the hippocampal CA3 network in memory. Front Cell Neurosci 7:98. CrossRef Medline

Rolls ET, Kesner RP (2006) A computational theory of hippocampal function, and empirical tests of the theory. Prog Neurobiol 79:1-48. CrossRef Medline

Sahay A, Scobie KN, Hill AS, O’Carroll CM, Kheirbek MA, Burghardt NS, Fenton A a, Dranovsky A, Hen R (2011a) Increasing adult hippocampal neurogenesis is sufficient to improve pattern separation. Nature 472:466470. CrossRef Medline

Sahay A, Wilson DA, Hen R (2011b) Pattern separation: a common function for new neurons in hippocampus and olfactory bulb. Neuron 70: 582-588. CrossRef Medline

Schmitz A, Grillon C (2012) Assessing fear and anxiety in humans using the threat of predictable and unpredictable aversive events (the NPU-threat test). Nat Protoc 7:527-532. CrossRef Medline

Segal SK, Cahill L (2009) Endogenous noradrenergic activation and memory for emotional material in men and women. Psychoneuroendocrinology 34:1263-1271. CrossRef Medline

Segal SK, Stark SM, Kattan D, Stark CE, Yassa MA (2012) Norepinephrinemediated emotional arousal facilitates subsequent pattern separation. Neurobiol Learn Mem 97:465-469. CrossRef Medline

Shackman AJ, McMenamin BW, Maxwell JS, Greischar LL, Davidson RJ (2009) Right dorsolateral prefrontal cortical activity and behavioral inhibition. Psychol Sci 20:1500-1506. CrossRef Medline

Shajahan PM, Glabus MF, Steele JD, Doris AB, Anderson K, Jenkins JA, Gooding PA, Ebmeier KP (2002) Left dorso-lateral repetitive transcranial magnetic stimulation affects cortical excitability and functional connectivity, but does not impair cognition in major depression. Prog Neuropsychopharmacol Biol Psychiatry 26:945-954. CrossRef Medline

Shrager Y, Kirwan CB, Squire LR (2008) Activity in both hippocampus and 
perirhinal cortex predicts the memory strength of subsequently remembered information. Neuron 59:547-553. CrossRef Medline

Slotema CW, Blom JD, Hoek HW, Sommer IE (2010) Should we expand the toolbox of psychiatric treatment methods to include repetitive transcranial magnetic stimulation (rTMS)? A meta-analysis of the efficacy of rTMS in psychiatric disorders. J Clin Psychiatry 71:873-884. CrossRef Medline

Squire LR (2009) Memory and brain systems: 1969-2009. J Neurosci 29: 12711-12716. CrossRef Medline

Squire LR, Bayley PJ (2007) The neuroscience of remote memory. Curr Opin Neurobiol 17:185-196. CrossRef Medline

Squire LR, Wixted JT (2010) The cognitive neuroscience of human memory since H.M. Annu Rev Neurosci 2011;34:259-288. CrossRef Medline

Sreenivasan KK, Curtis CE, D’Esposito M (2014) Revisiting the role of persistent neural activity during working memory. Trends Cogn Sci 18:8289. CrossRef Medline

Stark SM, Yassa MA, Lacy JW, Stark CE (2013) A task to assess behavioral pattern separation (BPS) in humans: data from healthy aging and mild cognitive impairment. Neuropsychologia 51:2442-2449. CrossRef Medline

Stern WM, Tormos JM, Press DZ, Pearlman C, Pascual-Leone A (2007) Antidepressant effects of high and low frequency repetitive transcranial magnetic stimulation to the dorsolateral prefrontal cortex. J Neuropsychiatry Clin Neurosci 19:179-186. CrossRef Medline

Stokes J, Kyle C, Ekstrom AD (2015) Complementary roles of human hippocampal subfields in differentiation and integration of spatial context. J Cogn Neurosci 27:546-559. CrossRef Medline

Stout DM, Shackman AJ, Larson CL (2013) Failure to filter: anxious individuals show inefficient gating of threat from working memory. Front Hum Neurosci 7:58. CrossRef Medline

Suthana NA, Donix M, Wozny DR, Bazih A, Jones M, Heidemann RM, Trampel R, Ekstrom AD, Scharf M, Knowlton B, Turner R, Bookheimer SY (2015) High-resolution 7T fMRI of human hippocampal subfields during associative learning. J Cogn Neurosci 27:1194-1206. CrossRef Medline
Tang H, Yu HY, Chou CC, Crone NE, Madsen JR, Anderson WS Kreiman, G (2016) Cascade of neural processing orchestrates cognitive control in human frontal cortex. Elife 5:e12352. Medline

Torrisi S, O'Connell K, Davis A, Reynolds R, Balderston N, Fudge JL, Grillon C, Ernst M (2015) Resting state connectivity of the bed nucleus of the stria terminalis at ultra-high field. Hum Brain Mapp 36:4076-4088. CrossRef Medline

Treves A, Rolls ET (1994) Computational analysis of the role of the hippocampus in memory. Hippocampus 4:374-391. CrossRef Medline

van Hagen BT, van Goethem NP, Lagatta DC, Prickaerts J (2015) The object pattern separation (OPS) task: A behavioral paradigm derived from the object recognition task. Behav Brain Res 285:44-52. CrossRef Medline

van Meurs B, Wiggert N, Wicker I, Lissek S (2014) Maladaptive behavioral consequences of conditioned fear-generalization: a pronounced, yet sparsely studied, feature of anxiety pathology. Behav Res Ther 57:29-37. CrossRef Medline

Vytal K, Cornwell B, Arkin N, Grillon C (2012) Describing the interplay between anxiety and cognition: from impaired performance under low cognitive load to reduced anxiety under high load. Psychophysiology 49: 842-852. CrossRef Medline

Vytal KE, Cornwell BR, Letkiewicz AM, Arkin NE, Grillon C (2013) The complex interaction between anxiety and cognition: insight from spatial and verbal working memory. Front Hum Neurosci 7:93. CrossRef Medline

Walling SG, Nutt DJ, Lalies MD, Harley CW (2004) Orexin-A infusion in the locus ceruleus triggers norepinephrine (NE) release and NE-induced long-term potentiation in the dentate gyrus. J Neurosci 24:7421-7426. CrossRef Medline

Warren SL, Crocker LD, Spielberg JM, Engels AS, Banich MT, Sutton BP, Miller GA, Heller W (2013) Cortical organization of inhibition-related functions and modulation by psychopathology. Front Hum Neurosci 7:271. CrossRef Medline 